\title{
Axonal Regeneration Contributes to Repair of Injured Brainstem-Spinal Neurons in Embryonic Chick
}

\author{
Sohail J. Hasan, Hans S. Keirstead, Gillian D. Muir, and John D. Steeves \\ Departments of Zoology and Anatomy, University of British Columbia, Vancouver, British Columbia, Canada V6T $1 Z 4$
}

Recent results have demonstrated complete anatomical and functional repair of descending brainstem-spinal projections in chicken embryos that underwent thoracic spinal cord transection prior to embryonic day 13 (E13) of the $21 \mathrm{~d}$ developmental period. To determine to what extent axonal regeneration was contributing to this repair process, we conducted experiments using a double retrograde tract-tracing protocol. On E8-E13, the upper lumbar spinal cord was injected with the first fluorescent tracing dye to label those brainstem-spinal neurons projecting to the lumbar cord at that time. One to two days later (on E10-E15), the upper to mid-thoracic spinal cord was completely transected. After an additional 7-8 $\mathrm{d}$, a different second fluorescent tracing dye was injected into the lumbar cord at least $5 \mathrm{~mm}$ caudal to the site of transection. Finally, 2 d later on E 19 to postnatal day 4, the CNS was fixed and sectioned. Brainstem and spinal cord tissue sections were then viewed with epifluorescence microscopy. In comparison to nontransected control animals, our findings indicated that there were relatively normal numbers of double-labeled brainstem-spinal neurons after a transection prior to E13, whereas the number of double-labeled and second-labeled brainstem-spinal neurons decreases after an E13-E15 transection. In addition, at each subsequent stage of development from E10 to $E 12$, there was a greater number of double-labeled brainstem-spinal neurons (indicating regeneration of previously severed axons) than cell bodies labeled with the second fluorescent tracer alone (indicating subsequent development of late brainstem-spinal projections). Assessment of voluntary open-field locomotion (hatchling chicks) and/or brainstem-evoked locomotion (embryonic or hatchling) indicated that functional recovery of animals transected prior to E13 was indistinguishable from that observed in control chicks (sham operated or unoperated). Taken together, these data suggest that regeneration of previously axotomized fibers contributes to the observed anatomical and functional recovery after an embryonic spinal cord transection.

\footnotetext{
Received May 5, 1992; revised July 22, 1992; accepted July 24, 1992.

We are indebted to Dr. Diane Henshel for her constructive comments and critical reading of the manuscript. We are also grateful to Dr. Deirdre Webster for all of her assistance. This work was supported by grants to J.D.S. from the Medical Research Council (MRC) of Canada and the B.C. Spinal Cord Society. S.J.H. was supported by a scholarship from the Natural Sciences and Engineering Research Council (NSERC) of Canada. H.S.K. was supported by a scholarship from the Network of Centres of Excellence for Neural Regeneration and Functional Recovery of Canada. G.D.M. was supported by a fellowship from the MRC of Canada.

Correspondence should be addressed to Dr. John D. Steeves, University of British Columbia, 6270 University Boulevard, Vancouver, B.C., V6T 124, Canada.
}

Copyright (C) 1993 Society for Neuroscience $0270-6474 / 93 / 130492-16 \$ 05.00 / 0$
IKey words: chicken, embryo, spinal cord, brainstem, brainstem-spinal pathways, injury, regeneration, anatomy, tract tracing, behavior, physiology, electrical stimulation]

Unlike the PNS, the CNS has a very limited capacity for regeneration. Damage to adult CNS axons after a spinal cord injury results in aborted attempts at regeneration, followed by degeneration (Ramon y Cajal, 1928; Bernard and Carpenter, 1950; Bjorklund et al., 1971). CNS axons do not regrow in the environment of the adult spinal cord. However, Aguayo and colleagues have demonstrated that CNS axons will anatomically regenerate if they are allowed to project through a PNS environment (David and Aguayo, 1981). These results dispelled previous suggestions that the lack of CNS axonal regeneration in higher adult vertebrates (i.e., birds and mammals) was due to the irreversible suppression of intrinsic growth programs within neurons. It is now generally accepted that, if CNS environmental conditions are favorable, adult CNS neurons should be capable of regeneration (e.g., Crutcher, 1989). In addition, a number of events in regeneration can be thought of as a recapitulation of development (Holder and Clark, 1988). Therefore, a better understanding of cmbryonic spinal cord development and repair is essential for assessing the conditions necessary for axonal regeneration in adult spinal cord.

Previous studies have shown that the embryonic chick is capable of axonal repair after complete transection of the thoracic spinal cord (Shimizu et al., 1990; Hasan et al., 1991). If the spinal transection was made prior to embryonic day 13 (E13; i.e., on E3-E12), the distribution and number of retrogradely labeled brainstem-spinal neurons were similar to sham-operated and unoperated control chicks. Transections conducted on E13 (or later) resulted in dramatically reduced retrograde labeling of brainstem nuclei.

The functional repair of descending supraspinal pathways was confirmed by behavioral observations of the motor functions of posthatching chicks (Shimizu et al., 1990) and also directly tested by focal electrical stimulation of brainstem locomotor regions known to have direct projections to the lumbar cord (Valenzuela et al., 1990; Hasan et al., 1991). Brainstem stimulation experiments were undertaken on both transected and control embryos (in ovo) on E18-E20. Leg and wing EMG recordings were used to monitor brainstem-evoked motor activity. In comparison to sham-operated and unoperated control animals, complete functional recovery of motor function was evident for chicks that had their spinal cord transected prior to E13 (Valenzuela et al., 1990; Hasan et al., 1991). Therefore, damaged embryonic spinal cord is capable of complete functional recovery after an E12 transection, but anatomical and functional repair rapidly diminishes with transections on 
E13-E14 and is completely nonexistent after an E15 transection (Shimizu et al., 1990; Hasan et al., 1991).

There are several neuroanatomical responses that could underlie this embryonic repair process, including (1) neurogenesis of new descending brainstem or spinal neurons, (2) subsequent projections from late developing brainstem-spinal neurons, or (3) true axonal regeneration of previously axotomized brainstem-spinal projections. Brainstem-spinal projections to the lumbar cord develop over a period extending from E4 to E10-E1 1 (Okado and Oppenheim, 1985; Hasan et al., 1991). It is known that brainstem-spinal neurons become postmitotic very early in development, usually prior to E5 (McConncll and Sechrist, 1980; Sechrist and Bronner-Fraser, 1991), and well before E12. Therefore, it is unlikely that the complete functional repair of an E7-E1 2 transected cord is dependent on the neurogenesis of additional brainstem-spinal neurons (Shimizu et al., 1990; Hasan et al., 1991). By E1 1 of normal embryonic development, the distribution and number of retrogradely labeled brainstem-spinal neurons are equivalent to those labeled in a chick after hatching (Okado and Oppenheim, 1985; Hasan et al., 1991). There is apparently no overproduction of locus ceruleus or reticulospinal neurons and subsequently no naturally occurring cell death of these neurons during development ( $R$. W. Oppenheim, personal communication).

Therefore, a mid-thoracic spinal transection at E7-E12 would disrupt the many descending projections already at lumbar levels. However, it is possible that the subsequent development of axonal projections, which had not descended to thoracic levels at the time of transection, may contribute to the functional recovery even after a transection as late as E11-E12. Since the development of brainstem-spinal pathways is nearly complete by $\mathrm{E} 11-\mathrm{E} 12$, it is more probable that the repair process involves axonal projections sprouting from the proximal ends of previously axotomized fibers (i.e., regeneration). Needless to say, these potential repair mechanisms are not mulually exclusive.

Here, we have investigated the contributions of these two mechanisms to embryonic spinal cord repair. By using two different retrograde fluorescent tracing labels, the first injected into the lumbar cord prior to thoracic transection and the second injected after transection, we have established that spinal cord repair in the latter stages of the permissive period (E10-E13) is increasingly due to true axonal regeneration.

\section{Materials and Methods}

Fertilized White Leghorn chicken eggs were incubated at $37^{\circ} \mathrm{C}$ in a humid incubator (relative humidity, 60\%). Complete development to hatching required $21 \mathrm{~d}$. Embryos were staged according to beak length (Hamburger and Hamilton, 1951). A small window $\left(1 \mathrm{~cm}^{2}\right)$ was made in each egg shell in order to access the embryo. Damage to the extraembryonic membranes, although unavoidable, was kept to a minimum. Embryos were positioned with the aid of a rounded glass probe passed under the neck.

\section{Anatomical assessments}

All animals are referred to throughout this article by the embryonic day (E) on which they were transected.

Experimental animals. The entire anatomical protocol (see below) was successfully completed on 31 animals that were either E10 (5), E11 (5), E12 (6), E13 (6), E14 (5), or E15 (4) at the time of spinal cord transection. Each animal underwent embryonic surgery on three separate occasions during development.

On E8-E13, the upper lumbar spinal column (L1-L2) was pierced with a glass micropipette (tip diameter, $30 \mu \mathrm{m}$ ) containing either an aqueous solution of rhodamine-labeled dextran-amine (RDA; 10,000 MW, lysine fixable, $25 \% \mathrm{w} / \mathrm{v}$ ), fluorescein-labeled dextran-amine (FDA;
$10,000 \mathrm{MW}$, lysine fixable, $25 \% \mathrm{w} / \mathrm{v}$ ), or cascade blue-labeled dextranamine (CBDA; 10,000 MW, lysine fixable, $25 \%$ w/v), which was then inserted into the spinal cord (Molecular Probes Inc., Eugene, OR). Each dye was diluted to a $25 \%$ concentration in $0.1 \mathrm{M}$ Tris buffer, $\mathrm{pH} 8.5$, containing $2.5 \%$ Triton X-100. Approximately $0.1-0.6 \mu$ l of RDA, FDA or CBD $\Lambda$ was pneumophoretically injected over a $1 \mathrm{~min}$ interval using a Picospritzer II (General Valve Corp., Fairfield, NJ) that was pressurized by nitrogen (3-30 psi). This procedure retrogradely labeled brainstem-spinal neurons that had projected to the lumbar cord at that stage of development (Fig. 1A; see also Fig. $3 A$ ). Note that potentially late developing neurons (neuron 2 in Fig. $1 A$ ) have not yet projected to the level of the lumbar cord where the first tracing dye was injected. Any late-developing neurons therefore remain unlabeled. The egg was then sealed with a sterile coverslip using paraffin and returned to the incubator.

One to two days later (on E10-E15), a complete spinal cord transection was made in the upper thoracic region ( $\mathrm{T} 4+1$ segment) using finely sharpened forceps (Fig. $1 B$ ). Note that some late-developing neurons (neuron 2 in Fig. $1 B$ ) may have not yet projected to the level of the transection site and therefore may not have been transected. Vertebral tissue surrounding the spinal cord transection site was also slightly damaged by this procedure. To assure that each transection procedure was complete, a $\# 00$ pin was then passed laterally through the entire spinal cord at the site of transection. The pin was previously marked for the depth of the spinal cord at that particular stage of embryonic development. The egg was again sealed with a sterile coverslip and returned to the incubator.

After an additional 7-8 d, a different second fluorescent tracing dye (RDA, FDA, or CBDA) was injected into the lumbar cord in a manner identical to the first injection (Fig. $1 C$ ). Note that late-developing neurons (neuron 2 in Fig. $1 C$ ) have now projected to the level of the lumbar cord where the second tracing dye is injected. Late-developing neurons would therefore be retrogradely labeled by only the second tracing dye. To prevent the second injected retrograde tracing dye from diffusing rostrally to and above the transection site thereby falsely labeling brainstem-spinal neurons, the second tracing dye was injected several spinal segments (at least $5 \mathrm{~mm}$ ) caudal to the lesion. In order to maintain comparable survival periods following spinal cord transection, embryos transected on E10-E12 received a second injection on E17-E20, while embryos transected on E13-E15 received a second injection on E20 to postnatal day $2(\mathrm{P} 2)$. Twenty-four to forty-eight hours after the second injection, the embryos were removed from their shells, and the omphalomesenteric (umbilical) veins and arteries were cut to allow exsanguination. Both embryos and hatchlings were then anesthetized with Somnotol (sodium pentobarbital, $75 \mathrm{mg} / \mathrm{kg}$, i.p.). The embryos and hatchlings were immediately perfused via the left ventricle over a 30 min period with $50 \mathrm{ml}$ of $0.9 \% \mathrm{NaCl}$ (containing $1000 \mathrm{IU}$ of sodium heparin) at $37^{\circ} \mathrm{C}$, followed by $50 \mathrm{ml}$ of $4 \%$ paraformaldehyde in $0.1 \mathrm{M}$ phosphate buffer $\left(\mathrm{pH} 8.5,20^{\circ} \mathrm{C}\right)$. The brain and spinal cord were postfixed for $24 \mathrm{hr}$ and then placed in $0.1 \mathrm{M}$ phosphate buffer saline containing $10 \%$ sucrose $\left(\mathrm{pH} 8.5,4^{\circ} \mathrm{C}\right)$. After $24 \mathrm{hr}$, the tissue was transferred to $30 \%$ sucrose in $0.1 \mathrm{M}$ phosphate buffer saline and stored at $4^{\circ} \mathrm{C}$ for subsequent histology.

Equivalent results were obtained with all three fluorescent tracing dyes (RDA, FDA, CBDA) regardless of the order in which they were injected. When two tracing dyes were mixed and injected together in order to detect the relative uptake of each dye, approximately equivalent numbers of brainstem-spinal neurons were retrogradely labeled with each dye and a maximum of $30 \%$ of the labeled cells contained both tracing dyes.

Control animals. Double lumbar injections of retrograde tracing chemicals were completed on 26 sham-operated control embryos (4 E10, 4 E11, 5 E12, 5 E13, 4 E14, 4 E15) and 12 unoperated control embryos ( 2 of each embryonic day from E10 to E15). The surgical procedures described above were also used for sham-operated controls. A small window $\left(1 \mathrm{~cm}^{2}\right)$ was made in each egg shell, and the embryo was positioned for surgery (using a rounded glass probe) without damaging the spinal cord or surrounding tissues. Transected, sham-operated, and unoperated embryos were treated the same with respect to incubation conditions.

To assess the completeness of the transection procedure, 14 experimental embryos that were transected at different developmental stages (2 E.10, 2 F.11, 3 F.12, 3 E13, 2 E14, 2 E15), were randomly selected from each group of eggs that had undergone transection. The spinal column was immediately removed following the transection procedure, 
Figure 1. Schematic representation of experimental procedure for retrograde double labeling of axotomized brainstem-spinal neurons. $A$, On E8-E13, the lumbar spinal cord was injected with the first fluorescent tracing dye. Note that neuron $l$ has reached the level of the lumbar cord but the late-developing neuron (2) has not yet reached the level of the lumbar cord where the first tracing dye is injected. Neuron $l$ therefore becomes retrogradely labeled with the first tracing dye while the late-developing neuron (2) remains unlabeled. $B$, The mid-thoracic spinal cord was completely transected 1-2 d later. Note that the axon of neuron $I$ is transected. The late-developing neuron (2), however, has not yet reached the level of the transection site and remains intact. $C$, After an additional 7-8 d, the second fluorescent tracing dye was injected into the lumbar cord, caudal to the site of transection. Note that both neuron $l$ and the late-developing neuron (2) have now reached the level of the lumbar cord where the second tracing dye is injected. Neuron 1 therefore becomes retrogradely double labeled while neuron 2 is retrogradely labeled by only the second tracing dye.

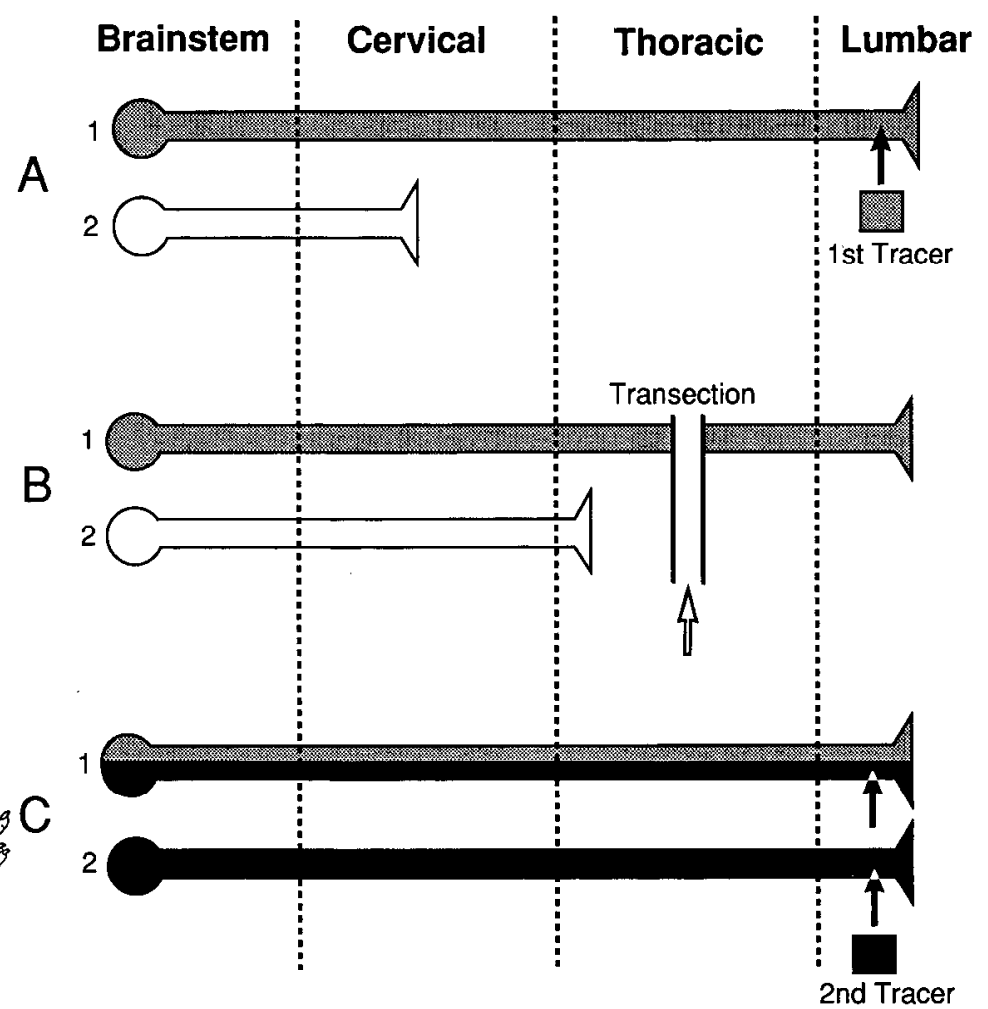

and histological techniques were used to examine whether the transection severed all spinal cord pathways.

Histology. The brain and spinal cord were cut at $30 \mu \mathrm{m}$ on a freezing microtome and the sections placed in $0.1 \mathrm{M}$ phosphate buffer ( $\mathrm{pH} 8.5$ at $4^{\circ} \mathrm{C}$ ). Brains were cut coronally and spinal cords were cut sagittally. Tissue sections were immediately mounted on slides for subsequent

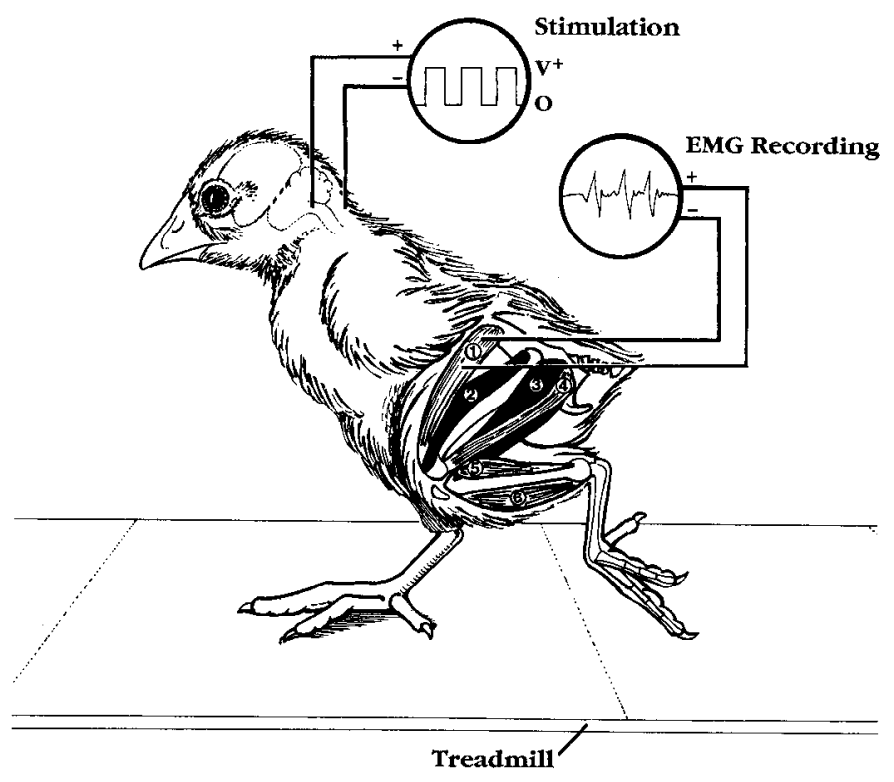

\begin{tabular}{|ll|}
\hline 1 & Sartorius \\
2 & Femorotibialis \\
3 & Iliofibularis \\
4 & Caudioflexorius \\
5 & Gastrocnemius Lateralis \\
6 & Tibialis Anterior \\
\hline
\end{tabular}

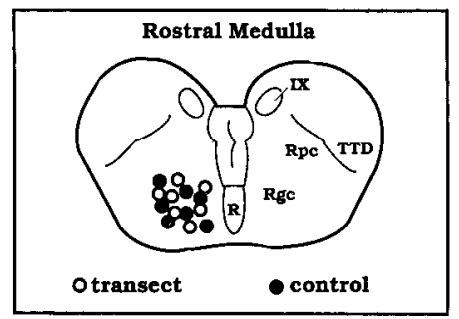

examination using a Zeiss Axiophot epifluorescent microscope equipped with standard filter blocks. Sections were photographed using Fujichrome 1600 daylight color reversal film push processed to 3200 ISO (Fuji). Exposure times ranged from 10 to $30 \mathrm{sec}$.

The positions of retrograde double-labeled neurons containing both the first and second injected dyes within the brain tissue section were mapped by eye onto drawings of brainstem tissue sections. Every third tissue section was counted. The positions of retrograde single-labeled neurons containing only the first or second injected dye (i.e., RDA, FDA, or CBDA) were also mapped. Brainstem nuclei were identified using several avian atlases (Karten and Hodos, 1967; Youngren and Phillips, 1978; Cabot et al., 1982; Gross and Oppenheim, 1985; Okado and Oppenheim, 1985; Kuenzel and Masson, 1988; Webster and Steeves, 1988). To allow comparisons between transected and control animals (sham-operated and unoperated), cell counts \pm the standard error (SE), and numerical range were obtained for each of several brainstem-spinal nuclei on the right side of each brain. Cell counts were obtained for the nucleus solitarius, nucleus centralis, nucleus reticularis gigantocellularis (Rgc), and nucleus raphes in the medulla; the nucleus vestibularis la-

\footnotetext{
Figure 2. Schematic representation of experimental procedures used for in vivo electrical stimulation (current strength, 15-50 $\mu \mathrm{A}$ ) of brainstem locomotor regions in transected, sham-operated, and unoperated 1-2 d old hatchling chicks. EMG recordings were utilized to monitor brainstem-evoked locomotor activity in six muscles of the right leg including the sartorius (hip flexor, knee extensor), femorotibialis (knee extensor), iliofibularis (hip extensor, knee flexor), caudioflexorius (hip extensor, knee flexor), gastrocnemius lateralis (ankle extensor), and tibialis anterior (ankle flexor) muscle. In addition, cither the sartorius, femorotibialis, or the gastrocnemius lateralis muscle of the left leg was implanted in order to record alternating leg activity. EMG recordings were also monilored in the PECT wing (wing depressor) muscles (not shown). Lower right panel shows diagram summarizing the positions of effective brainstem locomotor stimulation sites within the ventromedial reticular formation of the rostral medulla of sham-operated hatchlings (solid circles) and hatchlings that had their thoracic spinal cord transected on E10 or E12 (open circles). IX, N. nervi glossopharyngei; $R, \mathrm{~N}$. raphes; $R g c, \mathrm{~N}$. reticularis gigantocellularis; $R p c, \mathrm{~N}$. reticularis parvocellularis (medulla); $T T D, \mathrm{~N}$. et tractus descendens nervi trigemini.
} 
Table 1. Number (mean \pm SE) of single- and double-labeled brainstem-spinal neurons after temporally separated injections (shown in parentheses) of two different fluorescent retrograde tracing dyes into the lumbar cord

\begin{tabular}{|c|c|c|c|c|c|c|c|}
\hline \multirow[b]{2}{*}{ Tsx } & \multirow[b]{2}{*}{ Injection } & \multicolumn{2}{|l|}{ Rgc (medulla) } & \multicolumn{2}{|l|}{ VeL (pons) } & \multicolumn{2}{|c|}{$\begin{array}{l}\text { Nucleus interstitialis } \\
\text { (mesencephalon) }\end{array}$} \\
\hline & & Experimental & Control & Experimental & Control & Experimental & Control \\
\hline \multirow{4}{*}{ E10 } & 1st (E8) & $27.2 \pm 5.2$ & $18.3 \pm 3.4$ & $68.6 \pm 7.8$ & $52.2 \pm 7.2$ & $21.3 \pm 4.4$ & $28.1 \pm 3.6$ \\
\hline & 2nd (E18) & $33.4 \pm 3.3$ & $37.1 \pm 6.8$ & $78.9 \pm 8.1$ & $81.2 \pm 12.5$ & $96.4 \pm 8.8$ & $70.0 \pm 15.0$ \\
\hline & Double & $3.6 \pm 0.8$ & $4.2 \pm 1.2$ & $4.8 \pm 0.3$ & $7.8 \pm 2.1$ & $5.3 \pm 1.6$ & $8.0 \pm 2.8$ \\
\hline & $\%$ Double & 10.8 & 11.3 & 6.1 & 9.6 & 5.5 & 11.4 \\
\hline \multirow{4}{*}{ E12 } & 1st (E10) & $17.7 \pm 3.7$ & $14.1 \pm 1.1$ & $111.8 \pm 22.8$ & $102.0 \pm 4.2$ & $88.2 \pm 17.8$ & $79.1 \pm 9.7$ \\
\hline & 2nd (E20) & $27.7 \pm 1.0$ & $22.4 \pm 3.2$ & $96.1 \pm 27.2$ & $72.8 \pm 6.5$ & $80.4 \pm 7.7$ & $87.6 \pm 2.9$ \\
\hline & Double & $8.2 \pm 1.1$ & $6.5 \pm 1.6$ & $20.5 \pm 4.5$ & $23.9 \pm 7.4$ & $17.8 \pm 0.9$ & $22.9 \pm 3.1$ \\
\hline & $\%$ Double & 29.6 & 29.0 & 21.3 & 32.8 & 22.1 & 26.1 \\
\hline \multirow{4}{*}{ E14 } & 1 st (E12) & $31.7 \pm 6.4$ & $28.9 \pm 1.8$ & $85.6 \pm 18.1$ & $89.8 \pm 9.9$ & $79.5 \pm 7.1$ & $68.2 \pm 13.4$ \\
\hline & 2nd (P1) & $0.0 \pm 0.0$ & $36.3 \pm 2.4$ & $0.0 \pm 0.0$ & $97.6 \pm 6.8$ & $0.0 \pm 0.0$ & $72.3 \pm 5.6$ \\
\hline & Double & $0.0 \pm 0.0$ & $9.6 \pm 1.1$ & $0.0 \pm 0.0$ & $21.5 \pm 3.9$ & $0.0 \pm 0.0$ & $19.5 \pm 3.1$ \\
\hline & \% Double & 0.0 & 26.4 & 0.0 & 22.0 & 0.0 & 26.9 \\
\hline
\end{tabular}

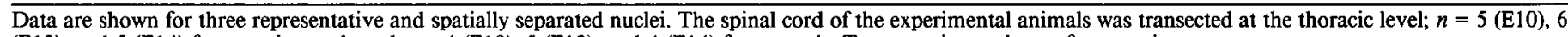
(E12), and 5 (E14) for experimentals and $n=4$ (E10), 5 (E12), and 4 (E14) for controls. Tsx, experimental age of transection.

teralis, locus ceruleus, nucleus subceruleus, nucleus reticularis pontis caudalis/pars gigantocellularis (RPgc), and nucleus raphes in the pons; and the nucleus interstitialis and nucleus ruber in the mesencephalon. The nucleus paraventricularis magnocellularis and stratum cellulare internum/externum were also examined for retrograde labeling.

The spinal cord tissue sections were examined for the extent of diffusion of the injected retrograde tracer chemical. There was never any evidence of the retrograde tracer diffusing rostrally to the level of the transection site.

\section{Behavioral observations and physiological assessments}

A second set of transected, sham-operated, or unoperated animals were used for the physiological assessments. These animals did not receive any injections of fluorescent tracing dye.

Hatching of operated chicks and behavioral observations. On E20-E21, eggs were placed in individual containers in the same incubator. When pipping occurred, the coverslip and paraffin were removed from the operated eggs and the chicks were allowed to hatch. Most of the embryos transected or sham-operated on E10-E12 hatched unassisted. Most embryos transected or sham-operated later in development (E13-E15) only reached the stage where they pipped the shell with their beaks, but failed to hatch. This implies that the spinal cord transection itself was not responsible for the hatching failure. We could successfully assist hatching by cracking open the egg shell and, if necessary, partially removing the chick from the shell and shell membranes when the following conditions were achieved: (1) the chick had pipped and was breathing on its own, (2) the chorioallantoic membrane had very little blood flow, and (3) the yolk sac had become enclosed within the body cavity. Locomotor activity (volitional walking or running toward a food reward) and conscious sensation (vocalization in response to toe pinch) were recorded in these transected and sham-operated chicks. Proprioception (the ability to right the body when placed on back) was also examined. These data were compared to data obtained from normal hatchlings.

Brainstem stimulation. Focal electrical stimulation of identified locomotor regions within the reticulospinal regions of the pontine and medullary reticular formation were undertaken on 20 (4 E10, $11 \mathrm{E} 12$, 5 E14) spinal-transected and 13 control animals ( $1 \mathrm{E} 10,2 \mathrm{El}$, and 2 E14 sham-operates and 8 unoperates) at the ages of P1 or P2. Brainstem stimulation was used to assess whether the observed anatomical regeneration also correlated with the functional repair of brainstem-spinal pathways. Brainstem-evoked motor responses were categorized on the basis of visual observations and electromyographic (EMG) recordings from leg muscles (see below). Detailed methodology is provided in Valenzuela et al. (1990) and Hasan et al. (1991).

For the preparative operation, hatchling chicks were deeply anesthetized with $3 \%$ halothane, $97 \% \mathrm{O}_{2}$ ( 2 liters $/ \mathrm{min}$ ). Thin, flexible bipolar hook electrodes were implanted in the sartorius, femorotibialis, iliofi- bularis, caudioflexorius, gastrocnemius lateralis, and tibialis anterior muscle of the right leg. In addition, either the sartorius, femorotibialis, or the gastrocnemius lateralis muscle of the left leg was implanted in order to record alternating leg activity (Fig. 2). Functions of these muscles are described in Jacobson and Hollyday (1982b). The pectoralis (PECT) muscles of each wing were also implanted. The PECT muscle is the major wing depressor (Weinstein et al., 1984). Chicks were allowed to recover (18-24 $\mathrm{hr}$ ) before recording.

Prior to the brainstem stimulation experiments, hatchling chicks were again deeply anesthetized with $3 \%$ halothane, $97 \% \mathrm{O}_{2}(2$ liters $/ \mathrm{min}$ ). The head was placed in a stereotaxic head holder. The calvarium and dura mater were resected and the cerebral hemispheres removed by suction along a plane extending dorsally from the habenular nucleus to the rostral extent of the optic chiasm ventrally. Upon completion of the decerebration, anesthesia was discontinued.

Brainstem regions within the ventromedial pontine and medullary reticular formation were sequentially probed with a monopolar stimulating electrode. Stimulation was in the form of alternating square wave pulses (pulse duration, $0.5 \mathrm{msec}$ ) at $60 \mathrm{~Hz}$. Electrical current strengths varied from 15 to $50 \mu \Lambda$.

Prior to the assessment of brainstem-evoked leg activity, electrical stimulation $(15-50 \mu \mathrm{A})$ of the ventromedial reticular formation had to first evoke synchronous wing flapping in each experimental and control hatchling. For experimental animals, the preceding thoracic spinal transection would not have disrupted any descending locomotor pathways to the cervical cord that controls wing movements. Thus, brainstemevoked wing flapping assured that the lightly anesthetized decerebrate hatchling was a healthy, viable animal and that all stimulation procedures were effective (see below). Consequently, any failure to evoke leg activity could not be due to the poor condition of an animal, nor could it be due to faulty experimental techniques. All 20 spinal transected animals and all 13 control chicks successfully demonstrated wing flapping in response to focal brainstem stimulation and were subsequently analyzed for evoked leg activity.

When a stimulation trial evoked locomotion (wing and/or leg) on a moving treadmill (speed, $0.1 \mathrm{~m} / \mathrm{sec}$ ), the lowest effective stimulation strength (threshold) was subsequently determined and the evoked locomotor EMG patterns were then recorded. EMGs were amplified $(1000 \times)$, bandpass filtered $(100-1000 \mathrm{~Hz})$, digitally converted (R. C. Electronics Inc., Santa Barbara, CA), and stored on computer disk. Following the stimulation trials, brainstem stimulation sites effective at eliciting leg movement were marked by making a small electrolytic lesion $(1 \mathrm{~mA} \mathrm{DC}$ for $5 \mathrm{sec})$.

At the end of the experiment, the hatchling was killed by decapitation and the brain and spinal cord were then removed and immersion fixed in $4 \%$ paraformaldehyde for subsequent histological confirmation of stimulation site. Standard histological techniques were used for preparation of brainstem tissue sections. 

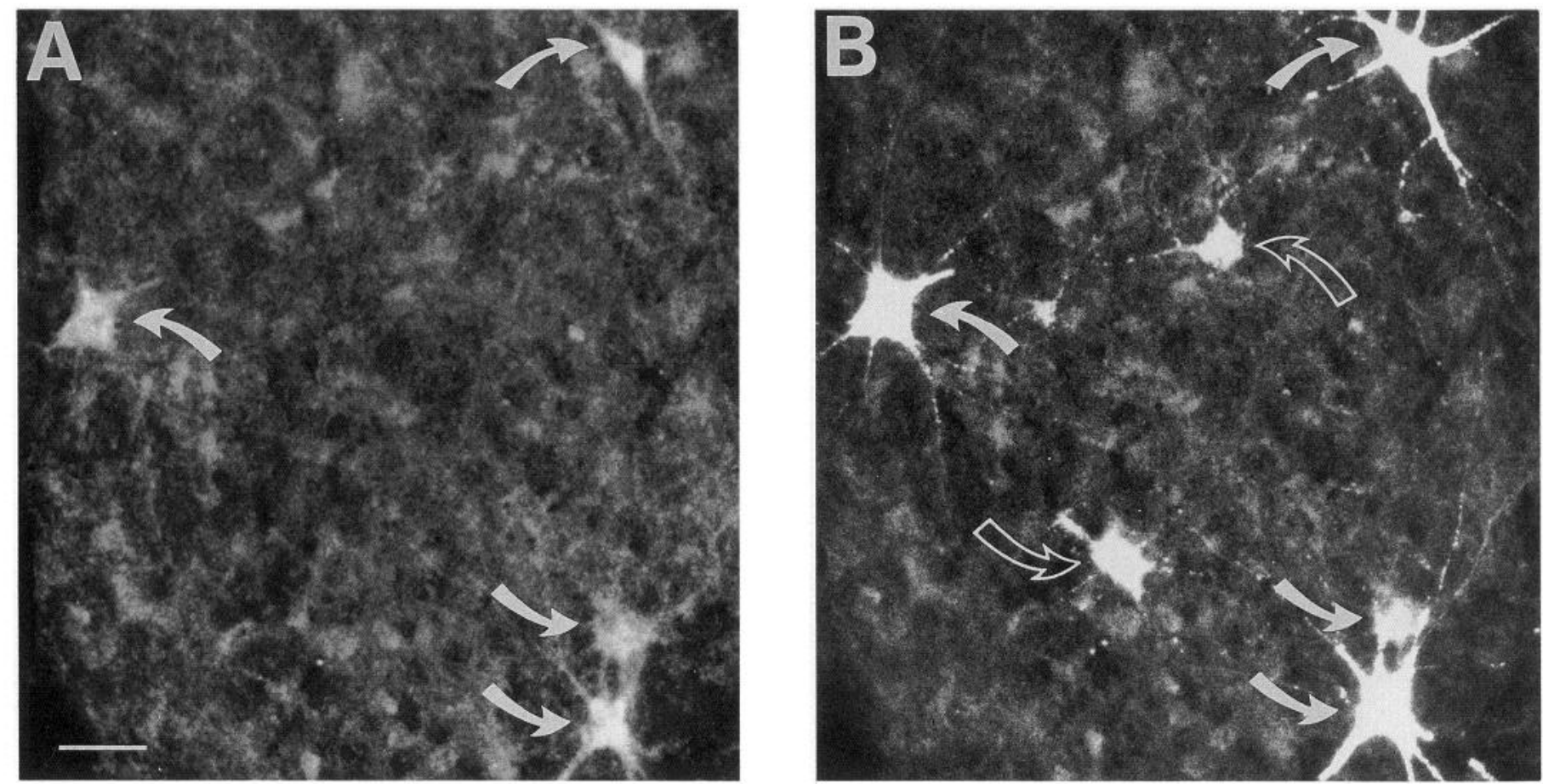

Figure 3. Photomicrographs of retrogradely labeled gigantocellular reticulospinal neurons within the ventromedial reticular formation of the caudal pons in E20 embryos previously transected on E11. A, Brainstem-spinal projections, present at the time of transection, were previously retrogradely labeled with a lumbar cord injection of the first label $(0.1 \mu \mathrm{l}$ of FDA) on E9. $B$, After the thoracic cord transection (E11), the second retrograde tracer $(0.3 \mu \mathrm{l}$ of RDA) was injected into the lumbar cord on E18. The presence of double-labeled brainstem-spinal neurons indicates regeneration of previously axotomized fibers, whereas the presence of single-labeled RDA neurons suggests subsequent projections from late-developing brainstemspinal neurons. Single-labeled neurons are indicated by open arrows, and double-labeled neurons are indicated by solid arrows. See Figure $4 D$ for the approximate location of photomicrographs in $A$ and $B$. Scale bar, $50 \mu \mathrm{m}$.

\section{Results}

\section{Anatomical assessments}

Results obtained from experimental animals will be discussed first, followed by results from control animals.

Experimental animals. Complete anatomical protocols were carried out on 31 animals (see Materials and Methods for number of experimental animals that were transected at each developmental stage).

Table 1 is a summary of the number of single- and doublelabeled brainstem-spinal neurons for several nuclei in E10, E12, and E14 transected animals. Both control and transected data are shown. See Materials and Methods (Histology) for a complete list of those brainstem nuclei for which cell counts were obtained.

The mean number, range, and distribution of brainstem-spinal neurons labeled with the first dye (injected on E8-E13) increased for each subsequent stage of development up to E11.
These results were seen in every nucleus examined except for the Rgc (see Histology under Materials and Methods). This result is expected since the number and distribution of brainstem neurons with lumbar projections increases up to E10-E11 (Okado and Oppenheim, 1985; Hasan et al., 1991).

The mean number, range, and distribution of brainstem-spinal neurons labeled with the second dye only (injected on E17-P2) were not apparently different between animals transected on $\mathrm{E} 10, \mathrm{E} 11$, or E12. The mean number, range, and distribution of brainstem-spinal neurons retrogradely labeled with both the first and second dye (double-labeled neurons), however, increased for each subsequent stage of development from E10 to E12. These results were seen in every nucleus examined. For reasons unknown, however, double-labeled neurons in the nucleus ruber were observed in only 3 of 31 experimental animals and 2 of 38 control animals. The ratio of double-labeled brainstem-spinal neurons (indicating regeneration of previously severed axons) to the number of neurons labeled with only the

Figure 4. Photomicrographs of retrogradely labeled gigantocellular reticulospinal neurons within the ventromedial reticular formation of the caudal pons in hatchling chicks. $A$ and $B$. Double-exposed photomicrographs of P1 hatchling brainstem-spinal projections retrogradely labeled with a lumbar cord injection of the first label $(0.1 \mu \mathrm{l}$ of RDA, red $)$ on E10 followed by a lumbar cord injection of the second label $(0.3 \mu \mathrm{l}$ of CBDA, blue $)$ on E20. $A$ is from a nontransected control, and $B$ is from an embryo transected on E12. The presence of double-labeled brainstem-spinal neurons (pink) indicates regeneration of previously axotomized fibers, whereas the presence of single-labeled CBDA neurons might suggest subsequent projections from late-developing brainstem-spinal neurons. Note the similar distribution and number of retrogradely double-labeled brainstemspinal neurons in $A$ and $B$ (see also Table 1). A few representative single-labeled neurons are indicated by open arrows, and a few representative (but not all) double-labeled neurons are indicated by solid arrows. $C$, Double-exposed photomicrograph of $\mathrm{P} 3$ hatchling brainstem-spinal projections retrogradely labeled with a lumbar cord injection of the first label (RDA) on E12 followed by a lumbar cord injection of the second label (CBDA) on P1 in an embryo transected on E14. The absence of single- or double-labeled brainstem-spinal neurons containing the second tracer (CBDA) indicates a lack of regeneration of previously axotomized fibers. $D$ indicates the location of photomicrographs in $A-C$. $C b$, cerebellum; $N V$, nervus trigeminus; $R P g c$, N. reticularis pontis caudalis, pars gigantocellularis. Scale bar, $50 \mu \mathrm{m}$. 

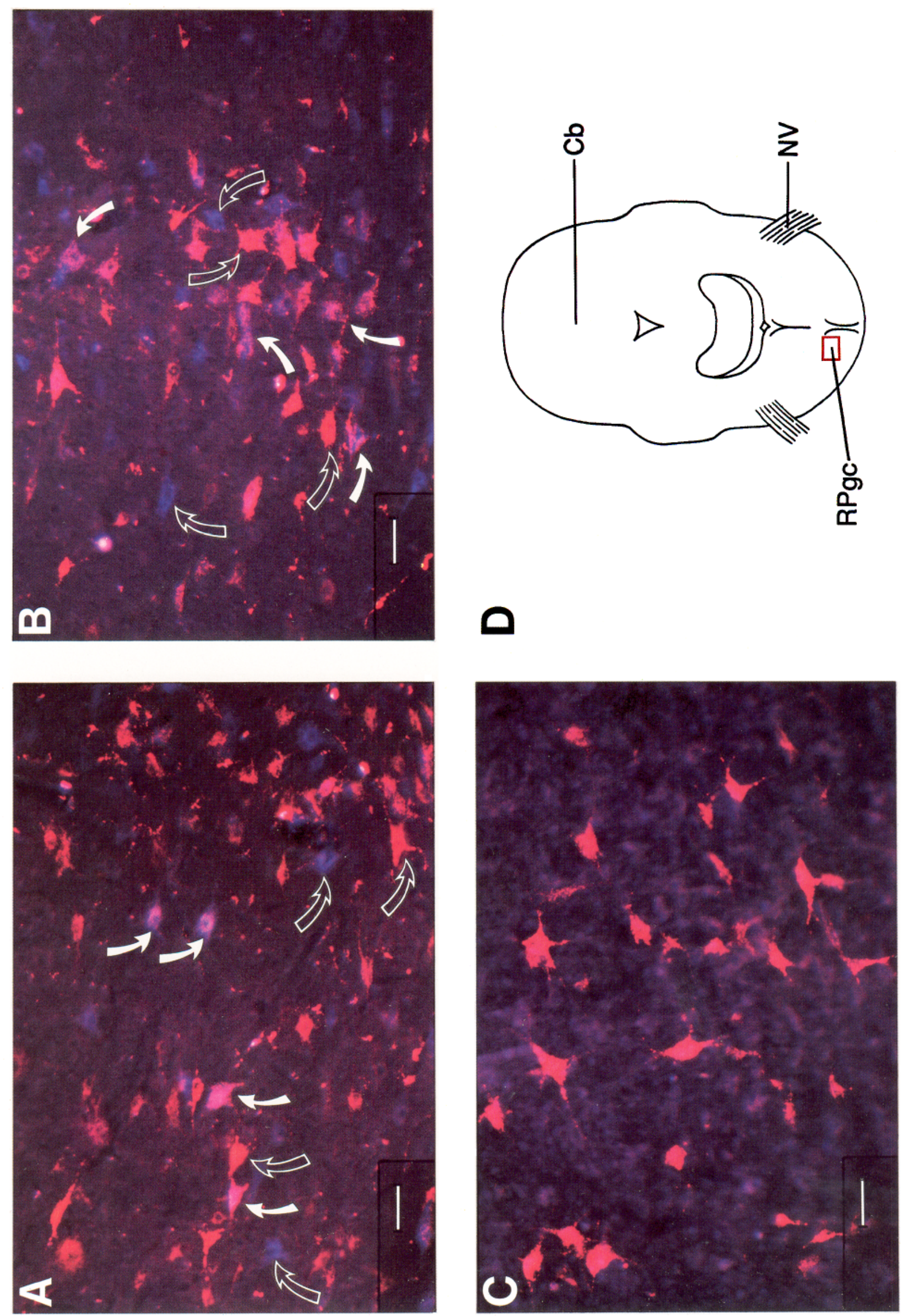

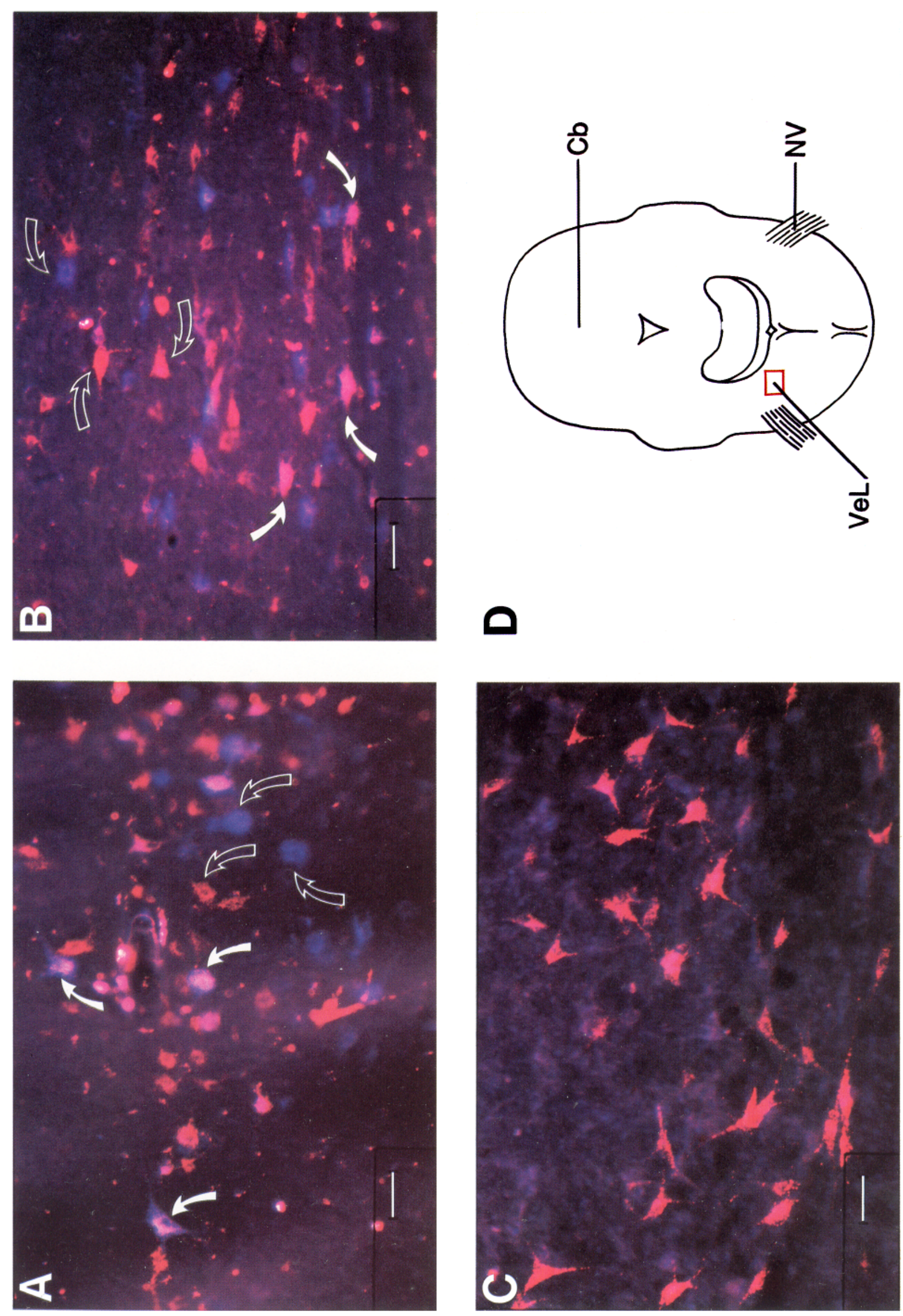

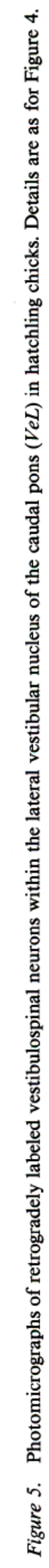


second fluorescent tracer (potentially indicating subsequent axonal development of late brainstem-spinal projections) is expressed as a percentage and is an index of regeneration by severed brainstem-spinal axons at that particular stage of embryonic development. We used the ratio of double-labeled brainstem-spinal neurons to the number of neurons labeled with only the second fluorescent tracer instead of the first fluorescent tracer because the number of neurons labeled with the first tracer increased in controls for each subsequent age of development up to E11. The number of neurons labeled with only the second fluorescent tracer, however, did not significantly differ between animals since the second dye was injected late in development (E17-P2). The mean percentage for brainstem-spinal neurons increased from $5.1 \%$ for animals transected on E10 to $21.7 \%$ for animals transected on E12. The index of regeneration was recalculated using the sum of neurons labeled with the first dye only plus neurons labeled with the second dye only in the denominator. The resultant change in the ratios from E10 to E12. were not apparently different from those reported above (see Table 1). In addition, very few labeled cells were found in the diencephalon of embryos transected on E10-E12.

The mean number, range, and distribution of brainstem-spinal neurons labeled with the second dye (injected on E17-P2) were much lower in animals transected on E13-E15 when compared to animals transected on E10-E12. The mean number, range, and distribution of brainstem-spinal neurons labeled with the second dye were clearly decreased in animals transected on E14 compared to animals transected on E13 since there were no double-labeled cells in animals transected on or after E14. The mean number of brainstem-spinal neurons double labeled with both the first and second dye also decreased with increasing age at transection. These results were consistent for all nuclei examined. The mean percentage of double-labeled neurons in all nuclei examined decreased from $2.9 \%$ for animals transected on E13 to $0.0 \%$ for animals transected on E15.

Figure 3 shows photomicrographs of retrogradely single- and double-labeled $\mathrm{RPgc}$ neurons within the ventromedial reticular formation of the caudal pons in an E20 embryo previously transected on E1 1 (during the permissive period). Figures 4 and 5 show double-exposed photomicrographs of brainstem sections from hatchling chicks retrogradely labeled following a transection during the permissive period $(B)$, the restrictive period $(C)$, and in a nontransected control embryo $(A)$. Figure 6 schematically summarizes these results. The presence of double-labeled brainstem-spinal neurons indicates regeneration of previously axotomized fibers, whereas the presence of single-labeled neurons suggests subsequent projections from late-developing brainstem-spinal neurons. The absence of double-labeled brainstem-spinal neurons following a restrictive period transection indicates a lack of regeneration of previously axotomized fibers. The absence of brainstem-spinal neurons containing the second tracer alone indicates a lack of late-developing brainstem-spinal projections contributing to repair.

Control animals. The extent of our spinal cord transection procedure was histologically confirmed in 14 randomly selected embryos operated on different days of embryonic development. In all cases, regardless of developmental stage, the spinal cord was completely severed at the thoracic level (see Hasan et al., 1991, their Figs. 2A, 3A). Since the same surgical procedure was undertaken on all experimental animals, we are confident that our surgical technique resulted in a complete transection of each embryo's spinal cord.

It was also necessary that we confirm that the injection of the first and second retrograde tracing chemical was confined to the caudal lumbar spinal cord. If the second fluorescent tracing dye (RDA, FDA, or CBDA) were to diffuse directly to the transection site (or perhaps even to more rostral spinal levels), then it could falsely label brainstem-spinal projections that had not descended caudal to the level of the transection site (i.e., had not regenerated). Histological examination of all spinal injection sites confirmed that the injected retrograde tracer was confined to within one or two segments of the rostral lumbar cord and did not diffuse rostrally to the transection site which was at least $5 \mathrm{~mm}$ away (see Hasan et al., 1991, their Figs. 2D, 3).

It was also critical that we discount the possibility that the first injected tracer remained in the spinal cord long enough for late-developing brainstem-spinal neurons to take up and retrogradely transport both the first and second fluorescent tracing dye simultaneously. A total of 12 embryos were used for this control experiment. Three E10 embryos received a lumbar injection of $0.2 \mu 1$ of CBDA followed by an immediate spinal cord transection rostral to the injection site. The transection served to prevent the retrograde transport of the first tracing dye to the cell bodies of origin in the brainstem. The same animals then received an injection of $0.3 \mu \mathrm{l}$ of RDA caudal to the transection site on E18. The presence of RDA-labeled neurons indicated repair of brainstem-spinal axons subsequent to the E10 transection. The lack of CBDA-labeled brainstem-spinal neurons indicated that this dye did not diffuse rostral to the site of transection, and that it did not remain viable for cotransport with RDA by axons projecting caudal to the site of transection (Fig. 7). An identical experiment (with three E10 embryos) was conducted in which the order of the dyes was reversed. That is, RDA was injected on E10 and CBDA was injected on E18. In this case, as expected, CBDA labeled neurons were present while RDA labeled neurons were not present.

Three E14 embryos received a lumbar injection of $0.1 \mu \mathrm{l}$ of CBDA followed by an immediate spinal cord transection rostral to the injection site. The same animals received an injection of $0.2 \mu$ of RDA caudal to the transection site on $\mathrm{P} 1$. The total lack of RDA-labeled neurons indicated little or no repair of brainstem-spinal axons subsequent to the E14 transection. The absence of CBDA-labeled brainstem-spinal neurons indicated that this dye did not diffuse across the site of transection. An identical experiment (with three E14 embryos) was conducted in which the order of the dyes was reversed. In this case, as expected, the same results (i.e., lack of RDA- or CBDA-labeled neurons) were obtained. Note that these experiments also ensure that the spinal cord was completely severed at the time of transection and that the first injected tracer did not directly diffuse rostrally to the site of transection.

Retrograde tracers were injected into the lumbar spinal cord of 26 sham-operated (4 E10, 4 E11, 5 E12, 5 E13, 4 E14, 4 E15) and 12 unoperated ( 2 animals at each embryonic day from E10 to E15) control animals. This was undertaken to determine the maximum number and distribution of double-labeled brainstem-spinal neurons with lumbar projections for each developmental stage. The numbers and distribution of retrograde single- and double-labeled neuronal cell bodies found in identified brainstem nuclei were equivalent to the experimental animals that received a thoracic spinal cord transection on El0-E12. 

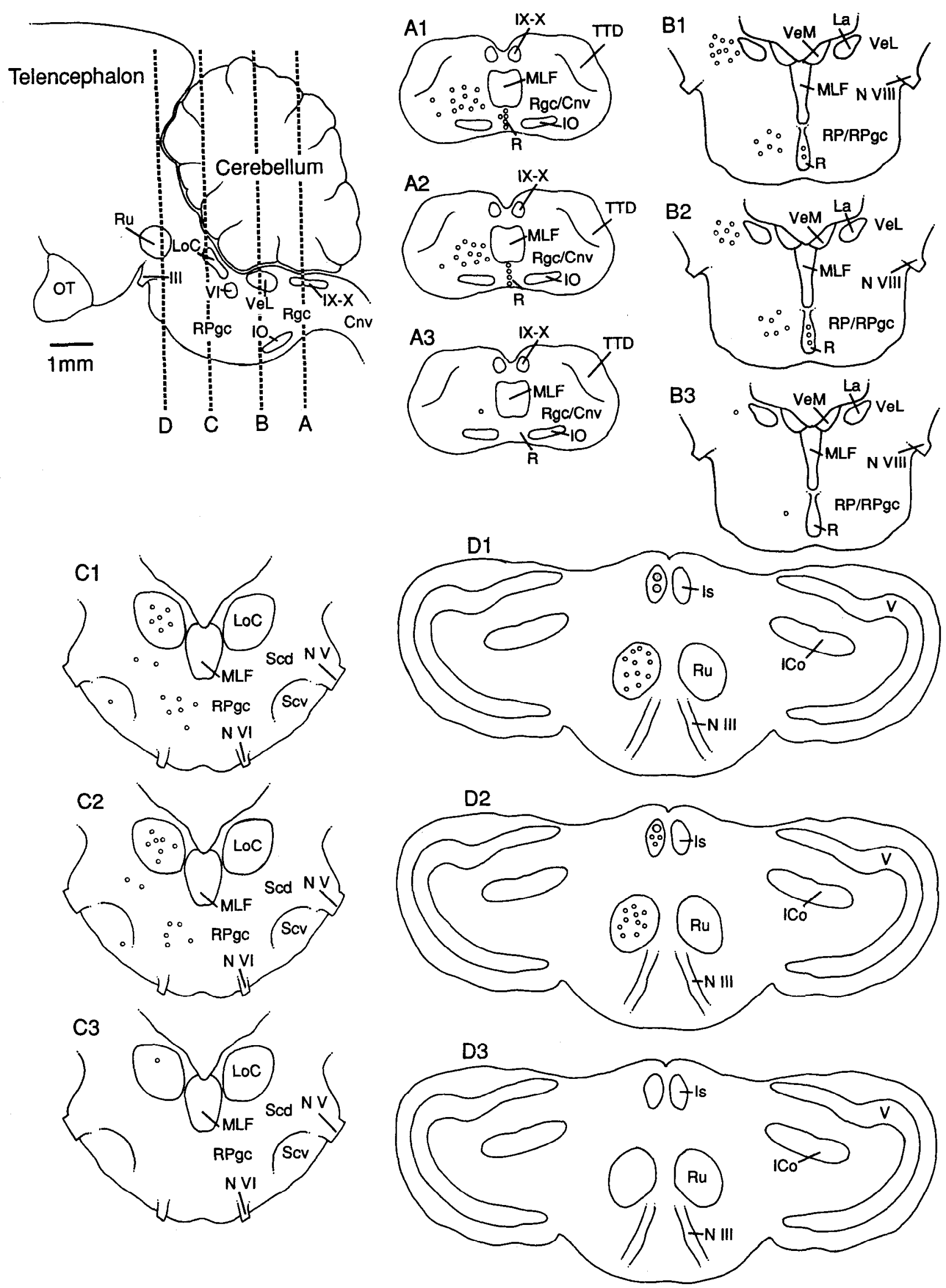
Table 2. Number of animals showing evoked stepping activity in response to focal electrical stimulation of a brainstem locomotor region on $\mathrm{P} 1$ or $\mathbf{P 2}$

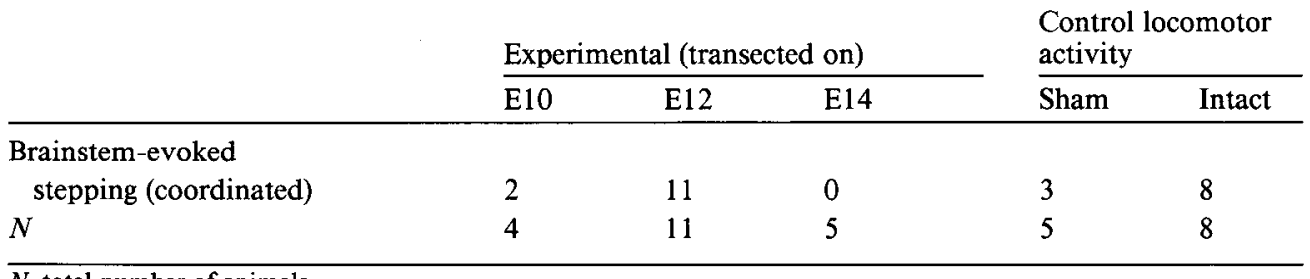

$N$, total number of animals.

(4 E10, $11 \mathrm{E} 12)$. All animals were healthy, ate and drank well, and showed no signs of discomfort. The E10-E12 transected chicks were able to walk, run, hop, and roll over in a manner that was indistinguishable from E10-E12 sham-operated control hatchling chicks. Of the four embryos sham-operated on E10-E12, three embryos hatched unassisted (one E10, two E12). Vocalization in response to toe pinch was the same for both groups. All E10-E12 transected, sham-operated, and all unoperated chicks exhibited similar goal-directed movement (volitional walking or running) toward a food reward.

Of the 12 embryos transected on E14, five embryos survived an assisted hatching. Of the five embryos sham-operated on E14, two embryos survived an assisted hatching. This suggests that disruption of the shell and chorioallantoic membranes and experimental movement of the embryo during any embryonic surgery after E1 2 may require that the embryo be assisted during hatching. Chicks transected on E14 had difficulty maintaining an upright standing posture. These chicks also had difficulty maintaining lateral stability and were only capable of taking a few stumbling steps. Conversely, chicks sham-operated on E14 showed normal posture, volitional walking, and running. After behavioral observation, all of the transected and control hatchling chicks were examined for brainstem-evoked locomotion (see below).

Brainstem stimulation. All embryonic brainstem stimulation experiments were performed on P1-P2. Focal electrical stimulation of discrete brainstem locomotor regions was undertaken on 20 experimental animals and 13 control hatchlings. The identified brainstem locomotor stimulation sites (Fig. 2; see also Steeves et al., 1987; Valenzuela et al., 1990) within the medial reticular formation correspond to $\mathrm{RPgc}$ and $\mathrm{Rgc}$, both of which have direct axonal projections to the lumbar spinal cord (Okado and Oppenheim, 1985; Steeves et al., 1987) and are identical to those brainstem regions showing retrogradely double-labeled brainstem-spinal neurons after a thoracic transection performed prior to E13 (see results above and Figs. 2-6). There were no significant differences in the motor responses evoked from the different brainstem stimulation sites. There were no significant or consistent differences in the cvokcd motor responses of embryos transected on E10 as compared to those embryos transected on E12.

Table 2 summarizes the number of chicks that had brainstem- evoked stepping (based on visual observations and EMG recordings of coordinated, rhythmical alternating activity from leg muscles). To differentiate between any spontaneous spinal generated activity and true brainstem-evoked leg locomotor activity, the leg movements had to commence with the onset of electrical stimulation and terminate with the offset of stimulation. Brainstem-evoked coordinated stepping ranged from a low of $0 \%(0$ of 5$)$ of the E14 transected embryos to a high of $87 \%$ (13 of 15) of the E10-E12 transected embryos. The percentage of E10-E12 transected animals that responded with coordinated stepping was comparable to the $85 \%$ average (11 of 13) for control hatchlings.

The thresholds for evoking coordinated locomotor activity were comparable in all animals (experimental and control) and averaged $25 \mu \mathrm{A}$ (range $=15-50 \mu \mathrm{A}$ ). When a brainstem locomotor region was effective in evoking locomotion on P1-P2, the muscle activity patterns were not significantly different among experimental hatchlings transected on or before E12, shamoperated, and unoperated control chicks (Fig. 8). In addition, the relationships between muscle burst duration and step cycle duration were similar for corresponding muscles in hatchling chicks transected on E12 and control chicks (Fig. 9). The step cycle duration for transected animals ranged from 0.1 to 1.6 sec, comparable to step cycle durations in control animals of $0.1-1.8 \mathrm{sec}$. Simultaneous brainstem-evoked stepping and wing flapping could also be evoked in E10-E12 transected chicks, and the EMG patterns of activity were similar to those evoked in control hatchlings. Finally, we found that in both the E10-E12 transected and control animals, an increase in the brainstem stimulation current strength evoked a faster stepping frequency (see Hasan et al., 1991). This further substantiates that the evoked stepping in the spinal transected and control groups was due to functional brainstem-spinal projections.

\section{Discussion}

The anatomical and physiological experiments reported here examined whether (and to what extent) axonal regeneration contributes to the recovery of brainstem-spinal projections after complete spinal cord transcction at various stages of embryonic development. When compared to control animals, our results demonstrate complete anatomical repair/regeneration and functional recovery of descending brainstem-spinal projections in

\section{$\leftarrow$}

Figure 6. Drawings summarizing the representative distribution and number of double-labeled brainstem-spinal neurons at four different levels of the brainstem: $A$, rostral medulla; $B$, caudal pons (at the level of the vestibular nuclei); $C$, rostral pons (at the level of the locus ceruleus); $D$, mesencephalon (at the level of the red nucleus). For each level $(A-D), I$ is an E20 control embryo, 2 is an E20 embryo transected on E11, and 3 is a P2 hatchling transected on E13. Note in all cases that the distribution and number of retrogradely double-labeled brainstem-spinal neurons are similar in a control and E11 transected embryo, but the number of retrogradely double-labeled neurons diminishes after a thoracic transection on E13 (see also Table 1). Small circles represent one retrogradely double-labeled brainstem-spinal neuron/tissue section; large circles in the nucleus interstitialis represent five retrogradely double-labeled brainstem-spinal neurons/tissue section. For abbreviations, see Appendix. 

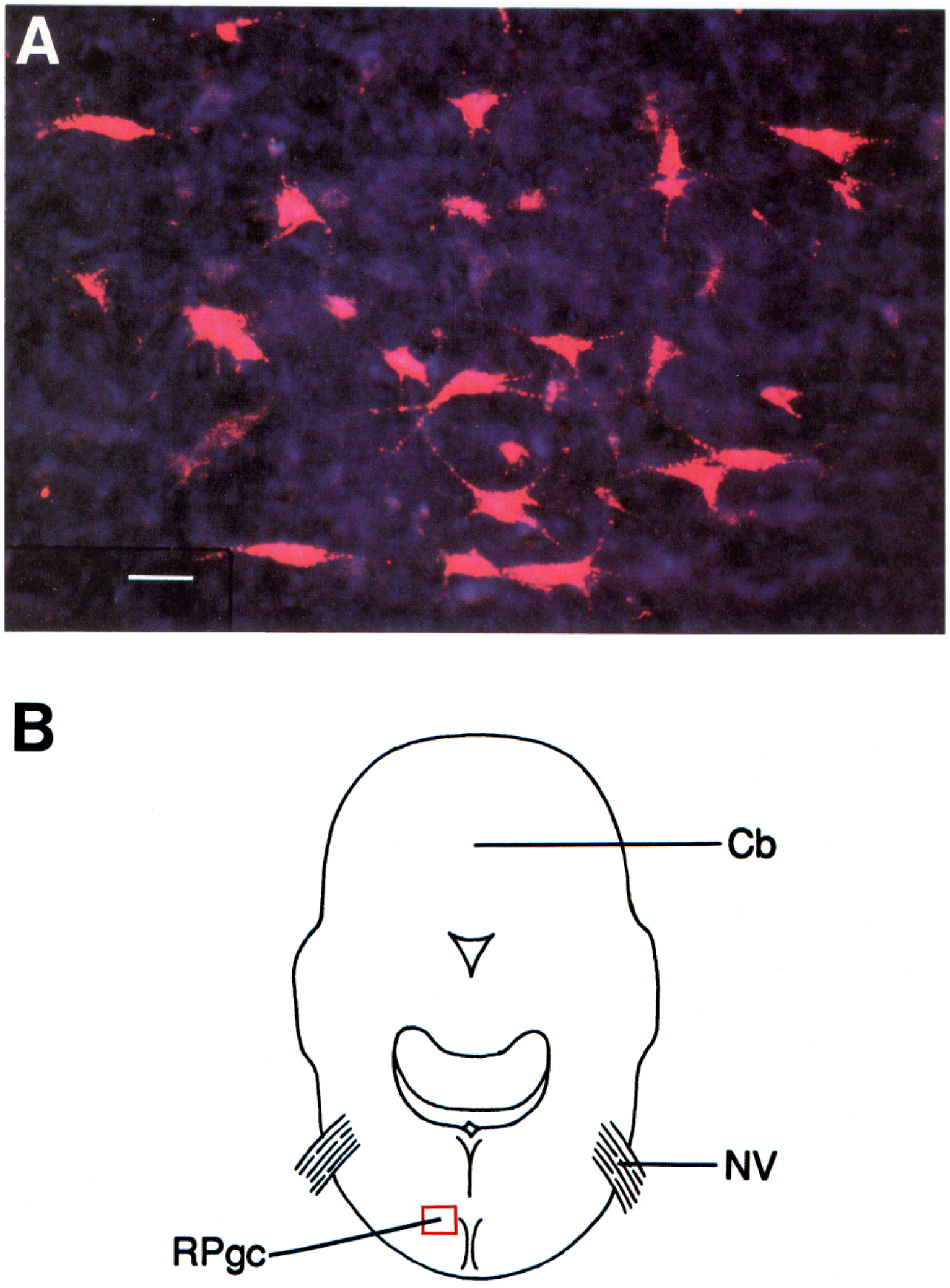

Figure 7. Double-exposed photomicrograph of retrogradely labeled gigantocellular reticulospinal neurons within the ventromedial reticular formation of the caudal pons in an E20 control embryo following an injection of $0.2 \mu 1$ of CBDA into the lumbar cord at E10 and an immediate spinal cord transection rostral to the injection site. The same animal subsequently received an injection of $0.3 \mu 1$ of RDA caudal to the transection site at E18. $A$, The lack of CBDA-labeled brainstem-spinal neurons indicates that this dye did not diffuse across the site of transection and that it did not remain viable long enough to be cotransported with RDA by axons crossing the site of transection. $B$ indicates the location of photomicrograph in $A$. $C b$, cerebellum; $N V$, nervus trigeminus; $R P g c, \mathrm{~N}$. reticularis pontis caudalis, pars gigantocellularis. Scale bar, $50 \mu \mathrm{m}$. 
embryos that underwent thoracic cord transection as late in embryonic development as E12. Our data also suggest that regeneration of previously axotomized fibers increasingly contributes to the observed anatomical and functional recovery after an embryonic spinal cord transection prior to E13. Embryos transected on E13-E15 showed only minimal anatomical repair/regeneration and functional recovery.

\section{Anatomical assessments}

There are a number of potentially confounding factors that must be considered before accepting our axonal regeneration results. These factors include (1) the completeness of the transection, (2) direct diffusion of the second tracing dye across the transection site, (3) the possibility of the first injected tracing dye remaining viable long enough for late-developing brainstemspinal neurons to retrogradely transport both the first and second dye simultaneously, (4) the variability in the quality or number of neurons labeled with each tracing dye, and finally, (5) transynaptic labeling of brainstem-spinal neurons via intrinsic spinal neurons. The first three issues have been addressed in the Results (sce Anatomical assessments) and can thus be dismissed as significantly confounding factors.

Regardless of which currently available anatomical tracing technique is used and no matter how rigorously standardized the methodology, it is well known that there can be variability between animals in the quality or number of neurons labeled by a retrograde tracing dye (Heimer and RoBards, 1981). Counting retrogradely labeled cells can lead to mistaken estimates (usually underestimates) about the number of neurons projecting to the injection site. By calculating the mean and SE of labeled cell numbers in control embryos and hatchlings, we were able to estimate the degree of variability inherent in our labeling technique and thus make comparisons between control and transected animals. The mean number of brainstem-spinal neurons labeled with the first injected dye (injected on E8-E13) increased for each subsequent stage of development up to E11. These results confirm our previous findings (Hasan et al., 1991) and those reported by Oppenheim and colleagues that brainstem-spinal projections complete development to the lumbar cord between E10 and E11 (Okado and Oppenheim, 1985; Shimizu et al., 1990). By calculating the ratio of double-labeled brainstem-spinal neurons (indicating regeneration of previously severed axons) to the number of neurons labeled with the second fluorescent tracer alone (potentially indicating the subsequent development of late brainstem-spinal projections), we determined an index for the extent of regeneration of severed brainstem-spinal axons at that particular stage of embryonic development. This ratio can be expressed as a percentage. The mean percentage increased from $5.1 \%$ for animals transected on E10 to $21.7 \%$ for animals transected on E12. The extent of regeneration decreased, however, for animals transected on or after E13. Note that these percentages are at best a conservative measure of the degree of axonal regeneration since the transport of both retrograde tracers in a brainstem-spinal axon required that the axon be damaged (see below) at the time of each injection. This could not be guaranteed.

We also considered the possibility that the labeling of brainstem-spinal neurons with the second retrograde tracer following spinal cord transection was due to transynaptic labeling via intrinsic spinal neurons that had descended below the transection site and contacted the second retrograde tracer. This can sometimes be a problem if the postinjection survival time is
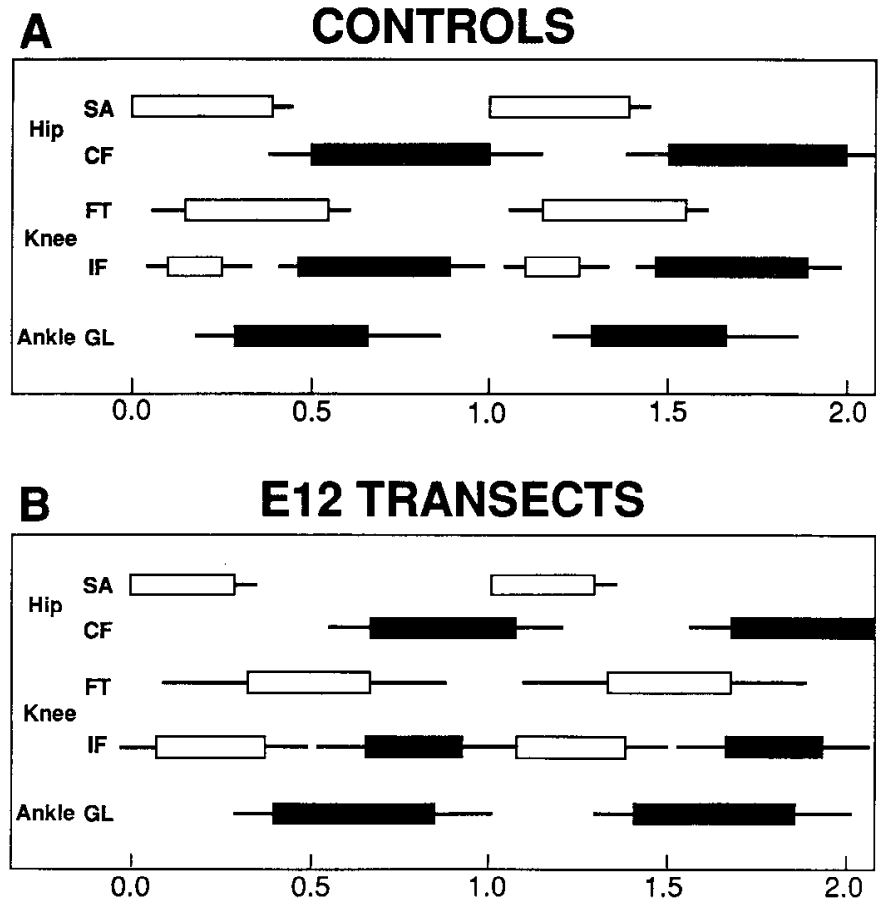

Figure 8. Summary of temporal relationships for leg muscle activity patterns during overground walking. Horizontal axis is time normalized for the duration of the step cycle. Two complete step cycles are presented in each diagram. Bars represent the proportion of the step cycle that each muscle is active: solid bars represent stance phase activity and open bars represent swing phase activity. Lines at the ends of each bar represent the SE for the onset/offset time for each muscle. $A$, Mean muscle activity pattern in control hatchlings $(n=6)$. The onset of activity of the sartorius muscle ( $S A$, hip flexor, knee extensor) has been shown to occur just prior to the onset of the swing phase of the step cycle (Jacobson and Hollyday, 1982a) and was considered here to be the beginning of the step cycle. The sartorius muscle continues to be active for most of the swing phase. The femorotibialis ( $F T$, knee extensor) and iliofibularis ( $I F$, hip extensor, knee flexor) muscles are also active during the swing phase. The iliofibularis muscle is active twice during each step cycle, once during the swing phase and once during the stance phase. The caudioflexorius ( $C F$, hip extensor, knee flexor), and gastrocnemius lateralis ( $G L$, ankle extensor) muscles alternate with sartorius muscle and are active during the stance phase. $B$, Mean muscle activity patterns in hatchlings that underwent spinal cord transection at E12 $(n=6)$. There were no significant differences from muscle activity patterns recorded in control hatchlings. The similarity of the muscle activity patterns of E12 transected hatchlings to those of control hatchlings supports the observation that E12 transected chicks show complete functional recovery.

long, as the dextran-amine dyes are transported transynaptically, although poorly. Since our postinjection survival time (following injection of the second retrograde tracer) was relatively short ( $48 \mathrm{hr}$ ), it is unlikely that transynaptic labeling contributed to the observed results. Furthermore, it has been shown that uptake of the fluorescent dextran-amines is very dependent on axon damage. Thus, they are not taken up by intact axons en passant, and uptake by terminals is much less efficient than by damaged axons (Glover et al., 1986). Finally, the distribution of brainstem-spinal neurons retrogradely labeled with the second tracer in E10-E12 transected embryos was the same as that seen in intact embryos, hatchlings, and adult birds (Okado and Oppenheim, 1985; Webster and Steeves, 1988; Hasan et al., 1991).

Transynaptic labeling within the brainstem was also ruled out. Only those brainstem nuclei with direct projections to the 


\section{CONTROLS}
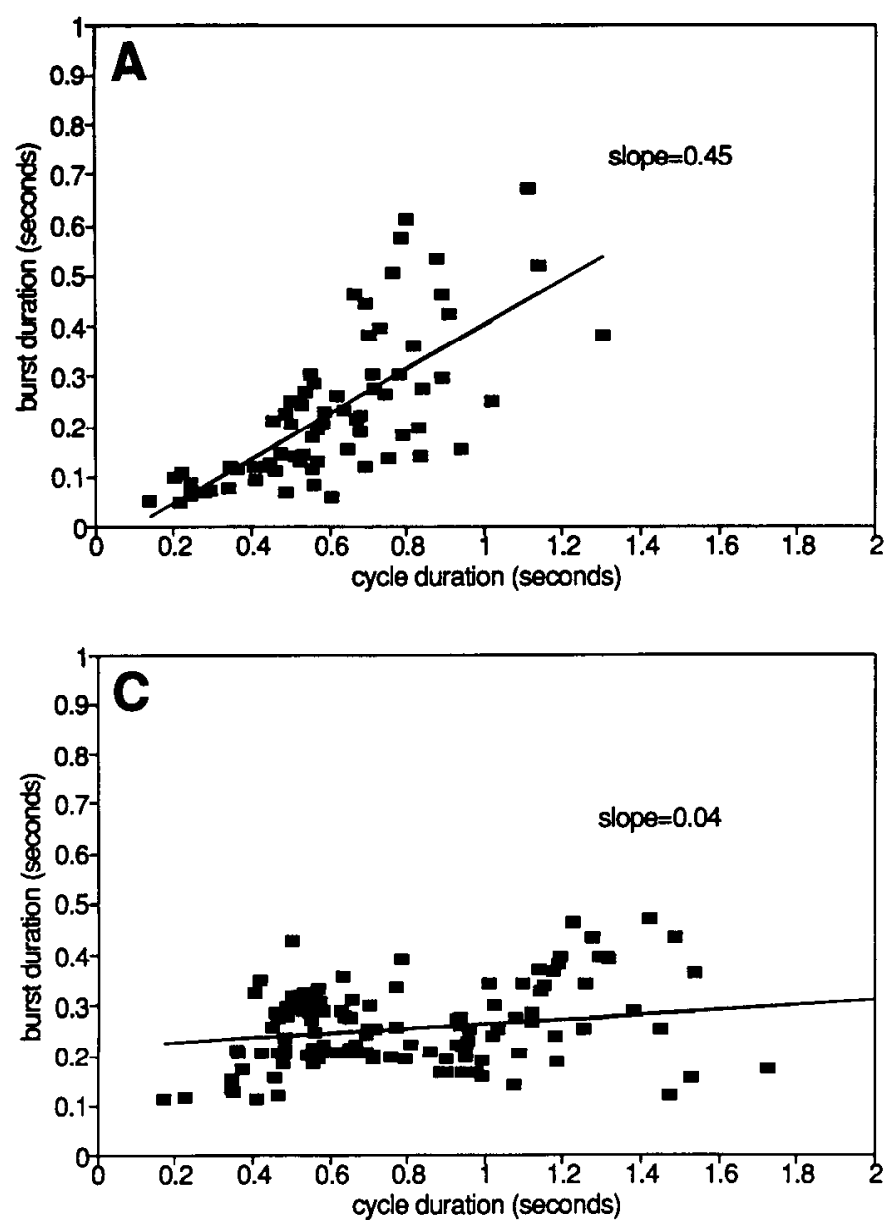

E12 TRANSECTS
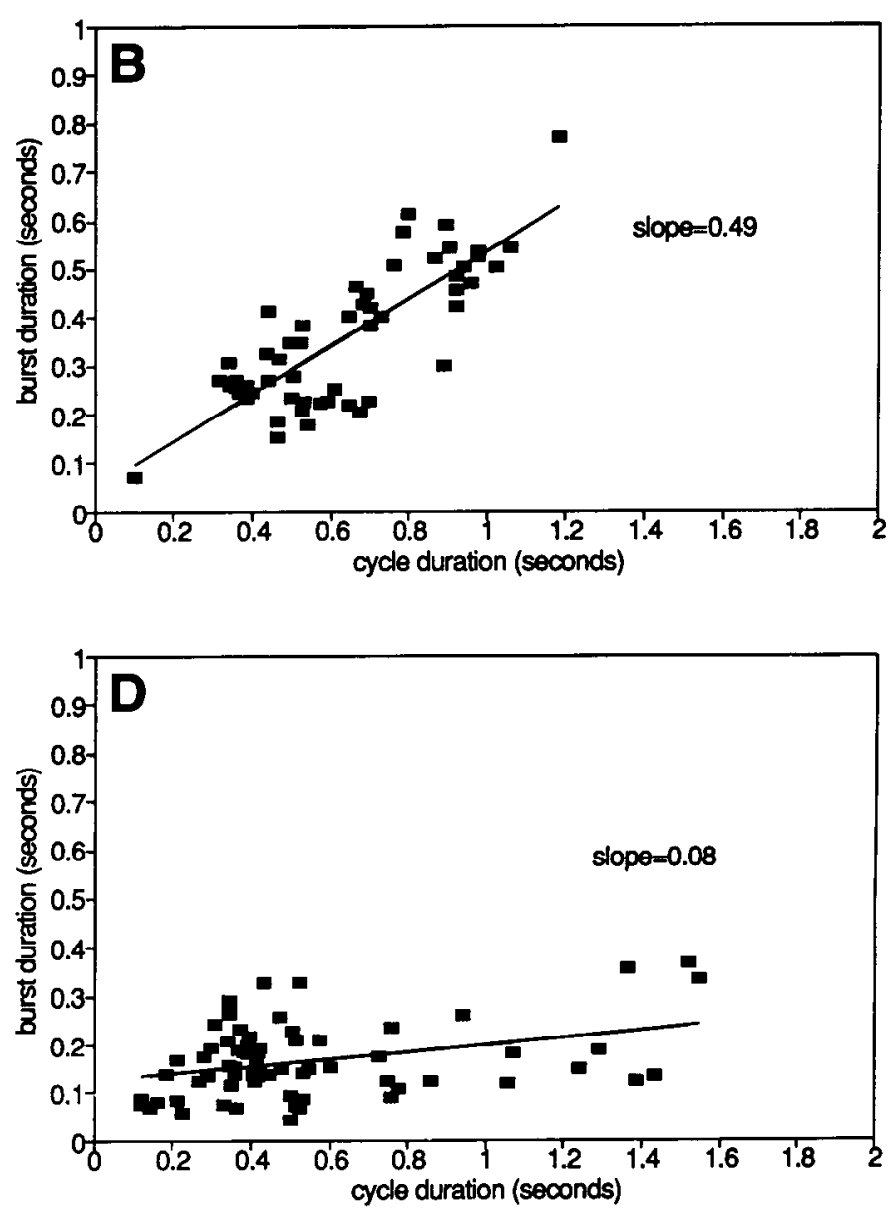

Figure 9. Linear regression of leg muscle activity (burst) duration versus step cycle duration for gastrocnemius lateralis (ankle extensor, stance phase) muscle $(A$ and $B$ ) and sartorius (hip flexor, knee extensor, swing phase) muscle ( $C$ and $D$ ) during brainstem-evoked locomotion of hatchling chicks. Typical of birds (Jacobson and Hollyday, 1982a), as cycle duration increases, the burst duration of the lateral gastrocnemius muscle increases $(A$ and $B)$ while the burst duration of the sartorius muscle remains constant $(C$ and $D)$. Control hatchlings $(A$ and $C)$ display the same relationships between burst duration and cycle duration as do E12 transected hatchlings ( $B$ and $D$ ), as indicated by the lack of significant difference between the slopes of the regression lines in $A$ and $B$ and between the slopes of the lines in $C$ and $D$. The similarity of the burst duration versus cycle duration relationships between control animals and E12 transected animals supports the observation that E12 transected chicks show complete functional recovery. $R^{2}=0.49,0.06,0.65$, and 0.13 for $A, B, C$, and $D$, respectively; $n=6$ for controls and $n=6$ for E12 transects.

lumbar spinal cord were labeled with the first, second, or both retrograde tracing dyes. No other brainstem nuclei (e.g., the nucleus vestibularis medialis) were retrogradely labeled. Very few labeled cells were found in the diencephalon of embryos transected on E10-E12. Experiments by other researchers (Webster and Steeves, 1988) confirm these results.

\section{Physiological assessments}

The physiological results also demonstrate complete functional repair of descending brainstem-spinal projections in hatchlings that underwent thoracic cord transection as late in embryonic development as E12. The extent of the functional repair was diminished or altogether absent in those hatchlings transected on E14. In order to ensure that any failure to evoke leg activity was not due to the poor condition of the animal or to faulty experimental techniques, brainstem-evoked wing flapping was assured prior to. examining evoked leg activity as an internal control for each animal.

After an embryonic spinal cord transection, brainstem-evoked leg activity can be accepted as a reliable indicator for the func- tional repair of brainstem-spinal projections if the following criteria are satisfied: (1) the leg activity must commence with the onset of brainstem stimulation and terminate with the offset of stimulation, (2) the leg activity must be evoked in response to current strengths that would not directly activate the spinal cord, (3) the pattern of leg muscle activity evoked in a transected hatchling should be similar to the pattern of evoked leg muscle activity in an unoperated or sham-operated control hatchling, (4) the relationships between muscle burst duration and step cycle duration should be similar for corresponding muscles in transected and control hatchlings, and (5) an increase in the brainstem stimulation current strength should evoke leg movements at a faster frequency. The present results satisfy all of the above criteria (see above and Figs. 8, 9).

\section{Factors contributing to the permissive period of spinal cord repair}

A number of intrinsic mechanisms may be contributing to the observed functional repair/regeneration of descending brainstem-spinal neurons after spinal cord transection prior to E13. 
The possibilities include (1) neurogenesis of new descending brainstem or spinal neurons, (2) subsequent projections from late-developing brainstem-spinal neurons, or (3) true axonal regeneration of previously axotomized brainstem-spinal projections.

Neurogenesis is not a likely mechanism for the repair observed following a thoracic spinal cord transection on E10-E12 because the brainstem-spinal pathways of birds become postmitotic on or before E5 (McConnell and Sechrist, 1980; Sechrist and Bronner-Fraser, 1991).

Our results in this and previous studies (Hasan et al., 1991) together with the work of Okado and Oppenheim (1985) suggest that brainstem-spinal projections have completed their projections to the lumbar cord by E11 and arc cquivalent in number and distribution to those observed in the hatchling chick. In other words, significant descending brainstem-spinal fibers are present within the thoracic cord at the time of an E10-E12 thoracic transection. It is highly unlikely, therefore, that the repair observed following a thoracic spinal cord transection on E10-E12 is exclusively due to subsequent projections from latedeveloping neurons. Also, the number and distribution of brainstem-spinal neurons retrogradely labeled with the second dye were similar in both E10-E12 transected and control chicks. This would not be the case if projections from late-developing neurons were substantially contributing to the repair process in E10-E12 transected chicks.

The presence of double-labeled brainstem-spinal neurons following a transection as late as E12 suggests that regeneration of previously axotomized fibers contributes to the observed anatomical and functional recovery. Terminal sprouting, or axon regrowth from the proximal cut end, has been implicated in the regeneration and restitution of function for brainstem-spinal projections in many lower vertebrates (Bernstein and Gelderd, 1970; Forehand and Farel, 1982; Clarke et al., 1988; McClellan, 1988, 1990; Davis et al., 1989; Lurie and Selzer, 1991). Anatomical evidence for regeneration has also been reported for brainstem-spinal projections in mammalian spinal cord (Bernstein and Bernstein, 1971; Goldberger, 1973; Goldberger and Murray, 1974; Puchala and Windle, 1977; Martin et al., 1979; Bregman and Goldberger, 1982; Bregman and Bernstein-Goral, 1991).

\section{Factors contributing to the restrictive period of spinal cord repair}

The diminished anatomical repair/regeneration of descending brainstem-spinal neurons in embryos transected on E13-E15 is unlikely to be attributed to a shorter posttransection recovery period. Care was taken to ensure that both E10-E12 transects and E13-E15 transects were allowed equivalent posttransection survival times (7-8 d). There is a possibility that animals transected late in development (e.g., on E14 or E15) could have a slower axonal regrowth rate compared to animals transected earlier (e.g., on E10 or E12). However, when the injection of the second dye was delayed as long as 3 weeks following an E14 transection, there were still no double-labeled neurons found in the brainstem (data not shown). Therefore, it is unlikely that a decrease in axonal regrowth rate is responsible for the lack of regeneration seen after an E14 or E15 transection.

Glial scarring may have acted as a physical barrier to prevent the subsequent growth or regrowth of brainstem-spinal neurons following a spinal cord transection on E13-E15. Like others, we were unable to detect any notable glial scarring upon histological examination of spinal cord sections following thoracic transections at different stages of embryonic development (Shimizu et al., 1990).

A spinal cord transection on or after E13 may have restricted blood supply to the spinal cord below the transection site. This is highly unlikely since physiological evidence (i.e., normal reflex activity) suggests that spinal neurons below the transection site remain viable after surgery (Okado and Oppenheim, 1984). This would suggest that the spinal vascular system must have been spared any permanent disruption.

Schnell and Schwab (1990) have recently provided anatomical evidence for axonal regeneration in the adult rat spinal cord produced by an antibody (IN-1) against certain myelin-associatcd protcins that inhibit the growth of neurons (Caroni and Schwab, 1988a,b; Schwab and Caroni, 1988). These results demonstrate the capacity for CNS axons to regenerate after the neutralization of myelin-associated neuron growth inhibitors. Owing to the difficulty of defining a clear function for the corticospinal tract in rats, one limitation of the Schnell and Schwab (1990) study was the inability to assess whether functional recovery of corlicospinal projections was improved by IN-1 treatment. The chick embryo is presently the only higher-vertebrate animal model providing evidence for both anatomical regeneration and functional recovery after complete spinal cord transection.

We are currently investigating different ways in which to inhibit myelin growth in an effort to enhance regeneration of damaged spinal cord neurons in the embryonic and adult chicken. The myelination of spinal cord fiber tracts in the embryonic chick begins at E13, coincident with the transition from permissive to restrictive repair states (Bensted et al., 1957; Macklin and Weill, 1985; Cameron-Curry et al., 1989). When a monoclonal antibody to galactocerebroside is injected into the E9-E12 thoracic spinal cord along with a source of serum complement, the onset of myelination is delayed until late in development (E17). This phenomenon has been referred to as dysmyelination. In such a dysmyelinated embryo, a subsequent transection of the thoracic cord as late as E15 then resulted in complete anatomical and functional recovery, demonstrating that the permissive period for spinal cord repair had been extended. These preliminary results support the suggestion that myelination is inhibitory to CNS repair and is the first demonstration that the suppression of myelin leads to functional recovery of transected spinal cord (Keirstead et al., 1992).

\section{Appendix}

\section{Anatomical abbreviations}

\section{$\mathrm{Cb} \quad$ Cerebellum}

OT Tractus opticus

\section{Medulla}

IX Nucleus nervi glossopharyngei

$\mathrm{X} \quad$ Nucleus motorius dorsalis nervi vagi

IO Nucleus olivaris inferior

MLF Fasciculus longitudinalis medialis

Cnv Nucleus centralis medullae oblongatae, pars ventralis

$\mathrm{Rgc} \quad$ Nucleus reticularis gigantocellularis

Rpc Nucleus reticularis parvocellularis (medulla)

R Nucleus raphes (medulla)

TTD Nucleus et tractus descendens nervi trigemini

\section{Pons}

VI Nucleus nervi abducentis

La Nucleus laminaris

MLF Fasciculus longitudinalis medialis 
$\mathrm{N}$ V Nervus trigeminus

N VI Nervus abducens

N VIII Nervus octavus

VeM Nucleus vestibularis medialis

VeL Nucleus vestibularis lateralis (Deiters')

$\mathrm{R} \quad$ Nucleus raphes (pons)

RP Nucleus reticularis pontis caudalis

$\mathrm{RPgc}$ Nucleus reticularis pontis caudalis, pars gigantocellularis

LoC Locus ceruleus

Scd Nucleus subceruleus dorsalis

Scv Nucleus subceruleus ventralis

\section{Mesencephalon}

III Nucleus oculomotorius

V Ventriculus

ICo Nucleus intercollicularis

Is Nucleus interstitialis

N III Nervus oculomotorius

$\mathrm{Ru} \quad$ Nucleus ruber

\section{References}

Bensted JPM, Dobbing J, Morgan RS, Reid RTW, Payling Wright G (1957) Neuroglial development and myelination in the spinal cord of the chick embryo. J Embryol Exp Morphol 5:428-437.

Bernard JW, Carpenter W (1950) Lack of regeneration in spinal cord of rat. J Neurophysiol 13:223-228.

Bernstein J, Gelderd J (1970) Regeneration of the long spinal tracts in the goldfish. Brain Res 20:33-38.

Bernstein JJ, Bernstein ME (1971) Axonal regeneration and formation of synapses proximal to the site of lesion following hemisection of the rat spinal cord. Exp Neurol 30:336-351.

Bjorklund A, Katzman R, Stenevi U, West KA (1971) Development and growth of axonal sprouts from noradrenaline and 5-hydroxytryptamine neurones in the rat spinal cord. Brain Res 31: 21-33.

Bregman BS, Bernstein-Goral H (1991) Both regenerating and latedeveloping pathways contribute to transplant-induced anatomical plasticity after spinal cord lesions at birth. Exp Neurol 112:49-63.

Bregman BS, Goldberger M (1982) Anatomical plasticity and sparing of function after spinal cord damage in neonatal cats. Science 217 : 553-554.

Cabot JB, Reiner A, Bogan N (1982) Avian bulbospinal pathways: anterograde and retrograde studies of cells of origin, funicular trajectories and laminar terminations. In: Descending pathways to the spinal cord (Kuypers HGJM, Martin GF, eds), pp 79-108. Amsterdam: Elsevier.

Cameron-Curry P, Dulac C, Le Douarin NM (1989) Expression of the SMP antigen by oligodendrocytes in the developing avian central nervous system. Development 107:825-833.

Caroni P, Schwab M (1988a) Two membrane protein fractions from rat central myelin with inhibitory properties for ncurite growth and fibroblast spreading. J Cell Biol 106:1281-1288.

Caroni P, Schwab M (1988b) Antibody against myelin-associated inhibitor of neurite growth neutralizes nonpermissive substrate properties of CNS white matter. Neuron 1:85-96.

Clarke JDW, Alexander R, Holder N (1988) Regeneration of descending axons in the spinal cord of the axolotl. Neurosci Lett 89:1-6.

Crutcher KA (1989) Tissue sections from the mature rat brain and spinal cord as substrates for neurite outgrowth in vitro: extensive growth on gray matter but little growth on white matter. Exp Neurol 104:39-54.

David S, Aguayo AJ (1981) Axonal elongation into peripheral nervous system "bridges" after central nervous system injury in adult rats. Science 214:931-933.

Davis BM, Duffy MT, Simpson SB (1989) Bulbospinal and intraspinal connections in normal and regenerated salamander spinal cord. Exp Neurol 103:41-51.

Forehand C, Farel PB (1982) Anatomical and behavioural recovery from the effects of spinal cord transection: dependence on metamorphosis in anuran larvae. J Neurosci 2:654-662.

Glover JC, Petursdottir G, Jansen JKS (1986) Fluorescent dextranamines used as axonal tracers in the nervous system of the chicken embryo. J Neurosci Methods 18:243-254.
Goldberger M (1973) Restitution of function and collateral sprouting in the cat spinal cord: the deafferented animal. Anat Rec 175-329.

Goldberger M, Murray M (1974) Restitution of function and collateral sprouting in the cat spinal cord: the deafferented animal. J Comp Neurol 158:37-54

Gross GH, Oppenheim RW (1985) Novel sources of descending input to the spinal cord of the hatchling chick. J Comp Neurol 232:162-179.

Hamburger V, Hamilton HL (1951) A series of normal stages in the development of the chick embryo. J Morphol 88:49-92.

Hasan SJ, Nelson BH, Valenzuela JI, Keirstead HS, Shull SE, Ethell DW, Steeves JD (1991) Functional repair of transected spinal cord in embryonic chick. Restor Neurol Neurosci 2:137-154.

Heimer L, RoBards MJ (1981) Neuroanatomical tract-tracing methods. New York: Plenum.

Holder N, Clark JDW (1988) Is there a correlation between continuous neurogenesis and directed axon regeneration in the vertebrate nervous system? Trends Neurosci 11:94-99.

Jacobson R, Hollyday M (1982a) A behavioral and electromyographic study of walking in the chick. J Neurophysiol 48:238-255.

Jacobson R, Hollyday M (1982b) Electrically evoked walking and fictive locomotion in the chick. J Neurophysiol 48:257-270.

Karten HJ, Hodos W (1967) A stereotaxic atlas of the brain of the pigeon (Columbia livia). Baltimore: Johns Hopkins UP.

Keirstead HS, Hasan SJ, Muir GD, Steeves JD (1992) Suppression of the onset of myelination extends the permissive period for the functional repair of embryonic spinal cord. Proc Natl Acad Sci, USA, in press.

Kuenzel WJ, Masson M (1988) A Stereotaxic atlas of the brain of the chick. Baltimore: Johns Hopkins UP.

Lurie DI, Selzer ME (1991) Axonal regeneration in the adult lamprey spinal cord. J Comp Neurol 306:409-416.

Macklin WB, Weill CL (1985) Appearance of myelin proteins during development in the chick central nervous system. Dev Neurosci 7:170-178.

Martin GF, Humbertson AO, Laxon LC, Panneton WM, Tschismadia I (1979) Spinal projections from the mesencephalic and pontine reticular formation of the North American opossum: a study using axonal transport techniques. J Comp Neurol 187:373-400.

McClellan AD (1988) Tunctional regeneration of descending brainstem command pathways for locomotion demonstrated in the in vitro lamprey CNS. Brain Res 448:339-345.

McClellan AD (1990) Locomotor recovery in spinal-transected lamprey: role of functional regeneration of descending axons from brainstem locomotor command neurons. Neuroscience 37:781-798.

McConnell JA, Sechrist J (1980) Identification of early neurons in the brainstem and spinal cord: an autoradiographic study in the chick. $\mathbf{J}$ Comp Neurol 192:769-783.

Okado N, Oppenheim RW (1984) Cell death of motoneurons in the chick embryo spinal cord. J Neurosci 4:1639-1652.

Okado N, Oppenheim RW (1985) The onset and development of descending pathways to the spinal cord of the chick embryo. J Comp Neurol 232:143-161.

Puchala E, Windle W (1977) The possibility of structural and functional restitution after spinal cord injury. A review. Exp Neurol 55: $1-42$.

Ramon y Cajal S (1928) Phenomena of necrosis, degeneration, and regeneration brought about by spinal contusion and laceration. In: Cajal's degeneration and regeneration of the nervous system [English transl] (DeFelipe J, Jones EG, eds), pp 558-582. New York: Oxford UP.

Schnell L, Schwab M (1990) Axonal regeneration in the rat spinal cord produced by an antibody against myelin associated with neuritegrowth inhibitors. Nature 343:269-272.

Schwab M, Caroni P (1988) Oligodendrocytes and CNS myelin are nonpermissive substrates for neurite growth and fibroblast spreading in vitro. J Neurosci 8:2381-2393.

Scchrist J, Bronner-Fraser M (1991) Birth and differentiation of rcticular neurons in the chick hindbrain: ontogeny of the first neuronal population. Neuron 7:947-963.

Shimizu I, Oppenheim RW, O’Brien M, Shneiderman A (1990) Anatomical and functional recovery following spinal cord transection in chick embryo. J Neurobiol 21:918-937.

Steeves JD, Sholomenko GN, Webster DMS (1987) Stimulation of the pontomedullary reticular formation initiates locomotion in decerebrate birds. Brain Res 401:205-212. 
Stoney SD, Thompson WD, Asanuma H (1968) Excitation of pyramidal tract cells by intracortical microstimulation: effective extent of stimulating current. J Neurophysiol 31:659-669.

Valenzuela JI, Hasan SJ, Steeves JD (1990) Stimulation of the brainstem reticular formation evokes locomotor activity in embryonic chicken (in ovo). Dev Brain Res 56:13-18.

Webster DMS, Steeves JD (1988) Origins of brainstem-spinal projections in the duck and goose. J Comp Neurol 273:573-583.
Weinstein GN, Anderson C, Steeves JD (1984) Functional characterization of limb muscles involved in locomotion in the Canada goose Branta canadensis. Can J Zool 62:1596-1604.

Wise RA (1972) Spread of current from monopolar stimulation of the lateral hypothalamus. Am J Physiol 210:1181-1186.

Youngren OM, Phillips RE (1978) A stereotaxic atlas of the brain of the three-day old domestic chick. J Comp Neurol 181:567-600. 